\title{
Priority AND Novelty UNDER THE AIA
}

\author{
Robert P. Mergest
}

\section{TABLE OF CONTENTS}

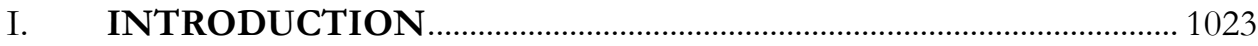

II. OVERVIEW OF THE AIA'S NOVELTY PROVISIONS ................ 1024

A. A SOMEWHAT SimPLER STRUCTURE ................................................... 1024

B. GeOgRAPHIC Distinctions Eliminated IN THE AIA ................ 1027

III. PRIORITY VERSUS NOVELTY......................................................... 1027

A. The Grace Period: A Complex Exception to the

PRIOR ART RULE.......................................................................... 1030

B. Disclosure AND Public Disclosure Under the AIA

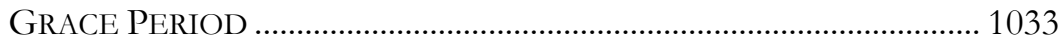

1. Confidential Sales and Non-informing Public Uses ........................... 1034

2. Aside: On "Secret Disclosures".......................................................... 1036

a) Prior-Filed Patent Applications as Secret

Disclosures .................................................................... 1037

3. "Public Disclosure": Meaning and Rationale .................................. 1038

a) Explaining "Public Disclosure" and the Grace

Period: Policy Rationale..................................................... 1042

b) Prior-filed Applications and Public Disclosures.......... 1044

\section{CONCLUSION: CONTINUITY AND CHANGE IN THE}

\section{INTRODUCTION}

The Leahy-Smith America Invents Act of 2011, Pub. L. No. 112-29, 125 Stat. 284 (2011) ("AIA") radically transforms some of the most basic rules in the U.S. patent system. For many inventors and patent owners the most important changes center on priority and novelty. Practitioners working under the new rules will need to understand three basic issues to be most

(C) 2012 Robert P. Merges.

† Wilson Sonsini Goodrich \& Rosati Professor of Law, University of California, Berkeley, School of Law. The author would like to thank Puneet Kohli for research assistance, and the BTLJ editorial board and staff for help in editing. Residual errors are all mine. 
helpful to their clients: (1) the critical date for most purposes is now the date that a patent application is first filed; (2) the prior art relevant to a given patent claim now consists of all references available under the statute prior to the filing date; and (3) priority contests between rival claimants to an invention will now be determined almost exclusively by looking to when each of the rivals filed their patent application. The discussion that follows elaborates a bit on these basic principles, and describes in general terms how they compare to the basic operating rules that pertain to the Patent Act of 1952 ("1952 Act") system of priority and novelty.

I begin with a brief explanation of the overall structure of the AIA's novelty provisions. I then consider the related yet distinct concepts of novelty and priority, and explain how the AIA changes the basic parameters of both these fundamental issues. I pay particular attention to two new statutory issues - the definition of "disclosure" and the creation of a "grace period" within which inventors can file a patent application. I conclude with some observations, sparked by the AIA, on continuity and change in the patent system.

\section{OVERVIEW OF THE AIA'S NOVELTY PROVISIONS}

\section{A. A SOMEWHAT Simpler STRUCTURE}

Overall, the AIA provides a somewhat simpler structure than the 1952 Act. Gone is the difference between novelty, strictly speaking, and the statutory bars under the 1952 Act. $^{1}$ The AIA eliminates the somewhat awkward structure of the 1952 Act, in which the related but distinct concepts of novelty and statutory bar appeared in successive subsections of $\int 102 .^{2}$

1. The caption to $\int 102$ of the 1952 Act reads: "Conditions for patentability; novelty and loss of right to patent." 35 U.S.C. \ 102 (2010). The latter phrase, "loss of right to patent," was clearly a reference to the statutory bars-which have the effect of cutting off an inventor's right to a patent unless he or she acts quickly after a prior art event. AIA \102(a), by contrast, is captioned "Novelty; Prior Art," a title that suggests the more uniform structure I am describing, and that at any rate eliminates the technical distinction between novelty and the statutory bars. The Leahy-Smith America Invents Act of 2011, Pub. L. No. 112-29, \3(b)(1), 125 Stat. 284, 285 (2011) (hereinafter “AIA").

2. The novelty and statutory bars under the 1952 Act were distinct concepts in two respects. Under the 1952 Act, only a third party can create novelty problems under $\$ 102(a)$, whereas anyone-including the inventor him or herself — can create prior art that serves as a statutory bar under 1952 Act $\int 102(\mathrm{~b})$. (Section 102(a): "the invention was known or used by others ..."; section 102(b): "the invention was described in a printed publication ... [not "by others"]). Indeed, in many cases, such as Egbert v. Lippmann, 104 U.S. 333 (1881), and Pfaff v. Wells Elec., Inc., 525 U.S. 55 (1998), it is the inventor himself that does somethingusing an invention in public, for example, or placing an invention on sale-that bars his ability to get a patent later. The AIA preserves elements of this distinction, but does so 
This means the end of the repetition of various categories or types of prior art under the two subsections, 1952 Act $\int 102(a)$ and $\ 102(b)-" p a t e n t e d$, printed publications," etc. It also means that the grace period concept, which had been buried in the structure and wording of 1952 Act $\int 102(\mathrm{~b})$, is much more apparent and prominent in the AIA. Under the new Act, the two distinct concepts of novelty and statutory bars are presented in a unified provision, AIA $\int 102$, which, first, states the rule that prior art appearing before the critical date deprives the inventor of his or her entitlement to a patent; second, defines all categories or types of references that qualify as prior art under the AIA (AIA \ 102(a)(1) and (2)); third, defines the critical date as the inventor's filing date (last phrase of AIA $\int 102(\mathrm{a})(1)$ and (2)); and fourth, identifies the grace period concept as an exception to the general rule that prior art appearing earlier than an inventor's filing date precludes patentability for the inventor's claimed invention.

In place of the 1952 Act structure, $\int 102$ under the AIA provides one simple novelty rule, and then lists exceptions to it, in the form of the grace period provision. ${ }^{3}$ The novelty rule, as mentioned, is keyed to the filing date. Additionally, however, the exceptions to the novelty rule-the situations in which an inventor might file a valid patent application even after otherwise invalidating information appears in the prior art-are stated in a distinct subsection. This contrasts with the old statutory bar provision of $\int 102(\mathrm{~b})$, which states that an inventor is entitled to a patent unless an invalidating reference appears more than a year before the inventor files a patent application. ${ }^{4}$ The notion of a one-year grace period is, of course, implicit in the 1952 Act phrase "[prior art appearing] more than a year before filing," but the AIA makes it much easier to see the purpose of this language. The AIA states the grace period in explicit, affirmative terms: "a disclosure made one year or less before the effective filing date shall not be prior art ... [if certain requirements are met]." 5 Thus, as stated, the rule makes it clear that the grace period has the effect of removing otherwise problematic prior art, so long as that art meets the requirements of the section and the inventor follows through by filing within a year of the date the prior art appears.

under a different structure. Instead of separating out novelty/anticipation into one category, and statutory bars (including the grace period) into another, the AIA melds the two concepts together into a section on "prior art," AIA $\$ 102(\mathrm{~b})$.

3. The AIA's amended $\int 102(\mathrm{a})(1)$ and (2) state the rule: no patent if, before filing of claimed invention, the invention was patented, described, etc. (the amended $\int(\mathrm{a})(1)$ ), or in a patent or application of another (the amended $\left.\int(a)(2)\right)$. AIA $\int 3(b)(1)$. Section 102(b) by its terms states "Exceptions"-i.e., the grace period provisions. Id.

4. 35 U.S.C. $\int 102(b)(2010)$.

5. AIA $\int 3(\mathrm{~b})(1)$. 
The best way to grasp this point is to read the new language of $\int 102$ in the AIA:

\102(a) NOVELTY; PRIOR ART.-A person shall be entitled to a patent unless-

(1) the claimed invention was patented, described in a printed publication, or in public use, on sale, or otherwise available to the public before the effective filing date of the claimed invention; or

(2) the claimed invention was described in a patent issued [to another] ... or in [another's] application for patent [that is] published ... [and that] was effectively filed before the effective filing date of the claimed invention.

(b) EXCEPTIONS.-

(1) DISCLOSURES MADE 1 YEAR OR LESS BEFORE THE EFFECTIVE FILING DATE OF THE CLAIMED INVENTION.-A disclosure made 1 year or less before the effective filing date of a claimed invention shall not be prior art to the claimed invention under subsection (a)(1) if-

(A) the disclosure was made by the inventor or joint inventor or by another who obtained the subject matter disclosed directly or indirectly from the inventor or a joint inventor; or

(B) the subject matter disclosed had, before such disclosure, been publicly disclosed by the inventor or a joint inventor or another who obtained the subject matter disclosed directly or indirectly from the inventor or a joint inventor.

(2) DISCLOSURES APPEARING IN APPLICATIONS AND PATENTS.-A disclosure shall not be prior art to a claimed invention under subsection (a) (2) if-

(A) the subject matter disclosed was obtained directly or indirectly from the inventor or a joint inventor;

(B) the subject matter disclosed had, before such subject matter was effectively filed under subsection (a) (2), been publicly disclosed by the inventor or a joint inventor or another who obtained the subject matter disclosed directly or indirectly from the inventor or a joint inventor; or

(C) the subject matter disclosed and the claimed invention, not later than the effective filing date of the claimed invention, were 
owned by the same person or subject to an obligation of assignment to the same person. ${ }^{6}$

Note that the phrase "effective filing date" generally refers to the filing of a patent application that establishes priority under U.S. law. This includes an application filed only in the United States, or at least first in the United States, and also certain applications filed first in foreign patent systems that are, by virtue of compliance with international treaties and U.S. law, granted the benefit of a U.S. filing date though initially filed elsewhere. ${ }^{7}$

\section{B. GeOgRAPHic Distinctions Eliminated IN THE AIA}

Speaking of foreign activity, the AIA continues a longstanding trend by eliminating more geographic distinctions in the definition of prior art. ${ }^{8}$ Under the 1952 Act, certain types or categories of prior art are within the prior art regardless of where they occur. ${ }^{9}$ Patents and printed publications are the best examples. Whether a patent is issued in Germany, Japan, or China, it is still within the prior art; so too with publications. But under the 1952 Act other types of prior art have geographic limits. ${ }^{10}$ Only "on sale" activities that occurred within the United States, for example, enter the prior art under the 1952 Act. $^{11}$ Foreign sales are not within the prior art. The AIA eliminates geographic distinctions for all categories of prior art. Under the AIA, if an event or activity occurs that meets the definition of prior art, it is within the prior art for U.S. patent law-regardless of where it occurs. ${ }^{12}$

\section{PRIORITY VERSUS NOVELTY}

For many casual observers, the innovations of the AIA of 2011 can be summarized by saying that the U.S. patent system has now moved from a "first-to-invent" system under the 1952 Act to a "first-to-file" system under the AIA. As a shorthand description, one can do worse. Yet this way of describing the AIA can also be a bit misleading. A deeper understanding of the relationship between the 1952 Act and the AIA is necessary to

6. AIA \102. Note that $₫ 102(\mathrm{c})$, "COMMON OWNERSHIP UNDER JOINT RESEARCH AGREEMENTS," deems subject matter disclosed and claimed by members of a joint research team to be "owned by the same person" under $\int 102(\mathrm{~b})(2)(\mathrm{C})$.

7. See AIA \3(a)(2)(i) (adding definition of "effective filing date" to $\int 100$ of the 1952 Act).

8. See generally Margo A. Bagley, Patently Unconstitutional: The Geographical Limitation on Prior Art in a Small World, 87 MiNN. L. REV. 679 (2003).

9. Id.

10. AIA $\int 102(\mathrm{~b})(1)$.

11. Id.

12. $I d$. 
understand the accuracy and limits of this label. As we shall see, there is good reason for the official or formal label given to the new novelty/priority system: first-inventor-to-file. Indeed, a more precise definition might be "first-proven-inventor-to-file," where proof takes the form either of an earlier filing date or a widely available disclosure.

One important issue in this respect is the difference between priority and novelty. Strictly speaking, priority is a question of who, as between two rival inventors, will obtain a patent for an identical invention. Priority, in other words, is a matter of "inventor vs. inventor"; whichever of the two is first (under the relevant rule) wins the patent. Novelty is a different matter. Novelty is a question of whether, as between an inventor and a piece of prior art, the inventor acts before or after the prior art enters the field. Novelty, then, is a matter of "inventor vs. prior art": if an inventor can show that he or she did whatever is required before a reference enters the prior art, the inventor gets a patent.

As between these two concepts, it is priority that is most clearly now a "first-to-file" regime. The AIA's first-to-file rule eliminates the need to decide which of two rival inventors actually invented first. In the vast majority of cases, the only relevant question under the AIA is which of the two rival inventors filed first. (The only exceptions are (1) where the first filer learned of or outright stole the invention from another person; and (2) where the second filer made a public disclosure of the invention before the first filer filed a patent application. In the first case, the PTO can undertake a "derivation proceeding" to sort out who is the rightful owner of the invention.) ${ }^{13}$ This eliminates the need for the expensive and drawn-out priority contests under the 1952 Act known as patent interferences. ${ }^{14}$

With this single stroke, the United States has resolved a longstanding debate over the relative merits of first-to-invent versus first-to-file priority. ${ }^{15}$ Two prominent arguments in this debate are worthy of mention. First, defenders of the traditional first to invent system often claim that it is required by the language of the patent and copyright clause of the constitution-i.e., that "exclusive rights to ... inventors" must necessarily

13. AIA $₫ 135$.

14. 35 U.S.C. $\$ 135$ (2010).

15. See, e.g., Dana Rohrabacher \& Paul Crilly, The Case for a Strong Patent System, 8 HARV. J.L. \& TECH. 263 (1995) (arguing in favor of first to invent); Mark A. Lemley \& Colleen V. Chien, Are the U.S. Patent Priority Rules Really Necessary?, 54 Hastings L. Rev. 1299 (2003) (reviewing arguments in favor of first to file, while not advocating complete adoption of this system). 
mean exclusive rights to proven first inventors. ${ }^{16}$ This is questionable as a matter of interpretation, ${ }^{17}$ but, even more importantly, the Supreme Court has spoken unequivocally in two recent copyright cases concerning Congress' very wide latitude in implementing the general language of the patent and copyright clause. ${ }^{18}$ For this reason, there is very little doubt that the constitutional objection to the first-to-file system will fail to gain much traction.

Second, the primary argument in favor of first-to-file, aside from international harmonization, is that whatever degree of extra fairness was achieved under the old first to invent system was purchased at an exorbitant price. That is, while advocates of a first to invent system can plausibly claim that their rule is fairer, the fact remains that in the majority of cases the firstto-file rule reaches the same result as the first-to-invent rule. ${ }^{19}$ And-here is the main point-it does so at a much lower cost. The extensive record keeping required to prove invention dates, together with the extremely high costs of conducting an actual interference, combine to make the first to invent system very expensive. ${ }^{20}$ The great benefit of the first-to-file system is that all these

16. This view is summarized nicely in Dennis Crouch, First to File and the Constitutional Argument, PATENTLYO Blog (June 11, 2011), http://www.patentlyo.com/patent/2011/06/ first-to-file-and-the-constitutional-argument.html.

17. Article I, Section 8 , Clause 8 of the U.S. Constitution reads in part: "The Congress shall have power ... To promote the Progress of Science and useful Arts, by securing for limited Times to ... Inventors the exclusive Right to their . . Discoveries." U.S. CONST. art. I, $\int 8, \mathrm{cl} .8$. Uses of the term "inventor" roughly contemporaneous with the ratification of the Constitution in 1789 demonstrate conclusively that the word was taken to mean "an inventor" as opposed to (necessarily) the first and original inventor. This is evidenced by a consistent usage under which the word "inventor" was not used to implicitly mean "first inventor," but when "first inventor" was meant it was said this way-i.e., with the modifier "first." See, e.g., John Freind, 2 History Of Physick 315 (1726) ("Dr. Willis, the first inventor of the nervous system."), cited in OXFORD ENGLISH DICTIONARY (electronic ed. 2010); JOHN RAY, CORRESPONDENCE 1659-1705 (1848) ("I am not sure that Mr. Newton was the first inventor of that plant"), cited in OXFORD ENGLISH DICTIONARY (electronic ed. 2010); Sir Henry Billinglsey, The Elements of the GeOMEtry of EuClid VOl. I24 (1570) ("Thales Mileseus ... was the first inventor of this proposition . . ."), cited in the OXFORD ENGLISH DiCTIONARY (electronic ed. 2010).

18. Golan v. Holder, 132 S. Ct. 873 (2012) (upholding constitutionality of provisions in Uruguay Round Amendments Act of 1994 which granted U.S. copyrights to foreign works formerly unprotected in the United States); Eldred v. Ashcroft, 537 U.S. 186 (2003) (extending copyright term to life plus seventy years did not violate constitution).

19. See Lemley and Chien, supra note 15 (documenting, based on a limited sample, that the same result is reached in a majority of cases).

20. See, e.g., Bernard R. Pravel, Why the United States Should Adopt the First-to-File System for Patents, 22 ST. MARY's L.J. 797, 799 (1991) ("The legal costs of an interference may be hundreds of thousands of dollars [in 1991 dollars] and may be difficult to avoid."). Some interferences last for many, many years and are presumably much more expensive even than 
costs are saved (except in cases involving a derivation proceeding or proof of an earlier public disclosure by the second-filer). Once the AIA takes effect, priority disputes will for the most part be resolved not by multi-year, complex administrative proceedings as in the old interference practice, but instead by recourse to a very simple decision rule: which application has the earlier date stamp on it? ${ }^{21}$

\section{A. The Grace Period: A Complex Exception to the Prior Art RULE}

Even so, an applicant's filing date is not always the only relevant consideration under the AIA. In a significant number of cases, an inventor who files after a piece of prior art appears in the field may still be entitled to a patent. The crucial question in these cases is this: did the inventor file within the AIA's statutory grace period? The AIA permits a significant set of exceptions to the general rule that, to be valid, an application has to be filed before a prior art event. The details of these exceptions pose some of the most difficult issues in interpreting the AIA — and will no doubt be a fruitful source of complex litigation issues when AIA patents begin to be filed, asserted against infringers, and ultimately brought before the PTO and federal courts.

One definitional issue is crucial to understanding the grace period. When AIA $\ 2$ refers to "disclosures," this is meant to include all the prior art categories set out in the new $\ 102(a)(1)$. This is apparent from the phrasing of the section, which reads: "A disclosure made 1 year or less before the effective filing date ... shall not be prior art under subsection (a)(1)." This provision explicitly equates the term "disclosure" with the content of the "prior art" under subsection (a)(1). The word "disclosure" here is equivalent to a single prior art reference. And of course it also implies the opposite case

this average figure. See, e.g., U.S. Steel Corp. v. Phillips Petroleum Co., 865 F.2d 1247 (Fed. Cir. 1989) (describing an enforcement action involving patent applications filed in the early to mid-1950s, resulting in an interference that lasted twenty-seven years); Andrew $\mathrm{H}$. Thorson, Japan's Patent System: An Analysis of Patent Protection Under Japan's First-to-File System (Part II), 77 J. PAT. \& TRADEMARK OFF. SOC’Y 291 (1995) (describing thirty-year interference costing six million dollars).

21. See Robert P. Merges \& John F. Duffy, Patent Law And Policy 449 (5th ed. 2011) (explaining that one of the principal justifications for a first-to-file rule is "administrative convenience"). Note too that in one of the two exceptional cases, the situation where A filed first but B can prove earlier public disclosure plus a filing by B within a year of that disclosure, the requirement that B show public disclosure should keep costs down somewhat. This is because a public disclosure is much easier to prove than some of the more obscure types of (non-public) disclosures in patent law. Discovery costs and proof at trial should as a result be more manageable. 
from the one stated: if a disclosure appearing one year or less before filing is not prior art, then one appearing earlier must be prior art.

Section 103 of the AIA adds further weight to this interpretation: "notwithstanding that the claimed invention is not identically disclosed as set forth in section 102," a claimed invention may still be obvious under $\int 103{ }^{22}$ Finally, note also that this understanding of "disclosure" carries over a usage that appears in $\int 103$ of the 1952 Act, which states that "though [an] invention is not identically disclosed or described as set forth in section 102," it may still be obvious under $\int 103 .^{23}$

So "disclosure" in the grace period provision, AIA $\int 102(\mathrm{~b})$, means any prior art reference as defined by AIA $\int 102(a)$. But which 102(b) disclosures qualify for the grace period? There are two general types: (1) those made by the inventor him or herself; and (2) those made by third parties, but only when the inventor him or herself had previously made a "public disclosure." We consider these one at a time.

Under AIA \102(b)(1)(A), an inventor has to file a patent application within one year from the time he or she discloses an invention. This is the essence of the grace period, and continues the practice established in the statutory bars under the 1952 Act.

AIA $\int 102(b)(1)(B)$ also establishes a grace period in some cases of thirdparty disclosure. But for an inventor to qualify for this grace period, he or she must "publicly disclose" prior to the time of the third-party disclosure. If an inventor does not publicly disclose before a third-party disclosure, there is no grace period for that inventor. This is a significant change from the statutory bar provision of the 1952 Act, which conferred a one-year grace period from the date of a prior event whether that event originated with an inventor (patent applicant) or a third party. ${ }^{24}$ Under the AIA, unless a third-

22. AIA $\int 103$.

23. 35 U.S.C. $\int 103$ (2010). Note further that one phrase in $\$ 102(a)(1)$ of the AIA might seem to suggest that the AIA excludes obscure prior art from consideration. Section 102(a)(1) says that a prior art reference can be a patent, a printed publication, in use or on sale activities, or "otherwise available to the public." AIA \102(a)(1). It should be clear from my arguments here that "disclosure" under the AIA connotes something "available to the public" without requiring widespread or openly accessible disclosure. Although we do not know yet what other categories of prior art a court might include under this omnibus "otherwise available" clause, we do know that this does not imply that the other categories must now be interpreted so as to include only widely accessible references. To restate my point: something can be "available to the public" in a limited way, and still be well short of "publicly disclosed" as that phrase is used in the grace period provision of the AIA.

24. See, e.g., Merges \& Duffy, PATENT LAW AND Policy 490 (5th. ed. 2011) (describing third-party $\int 102(\mathrm{~g})$ art under the $1952 \mathrm{Act}$ ); $i d$. at 529 (comparing first-party and third-party $\int 102(\mathrm{~b})$ prior art under the 1952 Act). 
party disclosure is preceded by an inventor's public disclosure, that thirdparty disclosure does not create a grace period. It is prior art, plain and simple, and the inventor's later patent application will fail the novelty test. (This, incidentally, is the closest the AIA comes to mimicking the "absolute novelty" or non-grace period rules in foreign patent systems such as the European Patent Convention.) $)^{25}$

But what if an inventor does publicly disclose before a third-party "disclosure" under AIA $\int 102(\mathrm{~b})$ ? Then, so long as the inventor files a patent application within one year of the inventor's disclosure, the inventor's patent application will pass muster under AIA $\int 102 .{ }^{26}$ Of course, as with the statutory bars, there are a good number of third-party "disclosures" that may be very difficult or impossible for the would-be patentee to discover, such as third-party confidential sales of the invention. So, the would-be patentee might well be quite in the dark regarding the time when the third-party disclosure takes place-and hence, regarding the end of the one-year grace

\section{Article 54 of the European Patent Convention reads:}

(1)

An invention shall be considered to be new if it does not form part of the state of the art.

(2)

The state of the art shall be held to comprise everything made available to the public by means of a written or oral description, by use, or in any other way, before the date of filing of the European patent application. $\ldots$

Convention on the Grant of European Patents art.54, Oct. 5, 1973, 1065 U.N.T.S. 199, available at http://www.epo.org/law-practice/legal-texts/epc.html. For more on this, see IAN Muir, Matthias Brandi-Dohrn \& STEPhan Gruber, European Patent Law: Law AND Procedure Under THE EPC AND PCT 177-89 (2d ed. 2002) (explaining EPC novelty and the very limited grace period of six months only when a public use or disclosure is based on an illicit acquisition of information from the true inventor).

26. As a technical matter under the statute, AIA $\int 102(\mathrm{~b})(1)(\mathrm{A})$ says that the third-party disclosure shall not be prior art if, before the disclosure, the "subject matter disclosed" had been preceded by a public disclosure on the part of the inventor/applicant. So strictly speaking under this subsection the one-year time bar applies to the third-party disclosure; this is the disclosure that is not prior art if it is preceded by the inventor. However, this does not mean that an inventor who publicly discloses prior to a third-party disclosure has one year from the third party's disclosure within which to file. There is no "grace period extension" where a third-party disclosure is preceded by an inventor's public disclosure. The reason is simple: an inventor's public disclosure is itself a disclosure under AIA $\int 102(\mathrm{a})$ and therefore it sets its own one-year time bar running. So if an inventor makes a public disclosure on January 1 of Year 1, and a third party makes a disclosure on February 1 of Year 1, the inventor still must file by January 1 of Year 2. If the inventor fails to do so, and files say on January 15 of Year 2, the application will fail the novelty test by virtue of the inventor's own disclosure on January 1 of Year 1. 
period triggered by that disclosure. But this is just as true of the statutory bars under the 1952 Act.

AIA $\int 102$ has a separate subsection that deals with prior-filed patents and patent applications. Section $\ 102(\mathrm{~b})(2)$ parallels the general structure of $\$ 102(\mathrm{~b})(1)$, but for the special case of disclosures in patents and applications. Section 102(b)(2) sets out a grace period in three situations: (1) when an applicant or patent owner is faced with an earlier-filed patent that was derived from that applicant-i.e., with a disclosure that originated with the inventor him or herself; (2) when an applicant is faced with a prior-filed patent, but that applicant had made a public disclosure of the material before the filing of the prior-filed patent; and (3) when an applicant is faced with a prior-filed patent that is owned by the same owner who owns the applicant's invention. The general structure of the AIA incorporates elements found in several provisions of the 1952 Act. The derivation issue in AIA $\int 102(\mathrm{~b})(2)(\mathrm{A})$ incorporates concepts from the 1952 Act derivation provision, $\int 102(\mathrm{f})$, for example. ${ }^{27}$ In addition, this part of the AIA tracks $\ 103(\mathrm{c})$ of the 1952 Act, which deals with common ownership situations.

\section{B. Disclosure and Public Disclosure Under the AiA Grace PERIOD}

As noted above, there are good reasons to read the term "disclosure" in AIA $\ 102(\mathrm{~b})$ to mean any prior art reference defined under AIA $\ 102(\mathrm{a})$. A disclosure under the AIA, then, means subject matter that is, prior to an applicant's filing date: "patented, described in a printed publication, or in public use, on sale, or otherwise available to the public," under AIA \102(a)(1); as well as subject matter "described in" a patent or published application, under AIA \102(a)(2).

The wording of many of these specific prior art categories was carried over from the 1952 Act, and indeed, many phrases originate in even earlier versions of the Patent Act. Many of the phrases have been the subject of extensive judicial interpretation over many years - making $\int 102$ one of many examples of what might be called a strong common law tradition in patent law. ${ }^{28}$ Many crucial terms in this body of law carry with them extensive case

27. 35 U.S.C. $\int 102(e)$, (f) (2010).

28. See Peter S. Menell, The Mixed Heritage of Federal Intellectual Property Law and Ramifications for Statutory Interpretation, UC Berkeley Public Law Research Paper No. 1895784 (2011), available at http://papers.ssrn.com/sol3/papers.cfm?abstract_id=1895784. 
law interpretations. ${ }^{29}$ It is generally understood, in patent law as elsewhere, that when Congress chooses to preserve legal language with an extensive body of interpretive case law behind it, that choice means that accepted case law interpretations are carried forward into the new legislative enactment. ${ }^{30}$ For purposes of the AIA, this general rule has some important consequences.

\section{Confidential Sales and Non-informing Public Uses}

Most importantly for present purposes, we need to take note of several of the prior art categories defined by traditional terms carried into AIA $\ 102$ : "in public use" and "on sale." According to an extensive body of case law, these prior art categories include material that can be quite confidential, or at any rate essentially undiscoverable by members of the general public. ${ }^{31} \mathrm{~A}$ consistent line of cases, for example, holds that confidential sales or offers place an invention "on sale" for purposes of 1952 Act $\ 102(b) .{ }^{32}$

The situation with respect to "public use" prior art is a bit more complex. The difficulty comes in cases where the output of an invented machine, or the end product of an invented process, is used in public-so-called "noninforming public use" cases. (They are called "non-informing" because the output or end product that is used publicly or placed on sale is incapable of informing the public about the nature of the actual invention, the underlying machine or process.) ${ }^{33}$ The cases on non-informing public use and sale have distinguished between the inventor's own activity and the activities of third

29. Id. at 9 (detailing early cases that fleshed out the meaning of statutory terms relating to utility and novelty). See also Craig Allen Nard, Legal Forms and the Common Law of Patents, 90 B.U. L. REV. 51 (2010).

30. See, e.g., Microsoft Corp. v. i4i Ltd. P’ship., 131 S. Ct. 2238, 2245 (2011) (“[W]here Congress uses a common-law term in a statute, we assume the 'term ... comes with a common law meaning, absent anything pointing another way.' ").

31. See, e.g., Buildex Inc. v. Kason Indus., Inc., 849 F.2d 1461, 1464 (Fed. Cir. 1988) (holding that a firm offer sent to prospective purchaser was an "on sale" event, despite the fact that the offer was marked "confidential"); In re Hall, 781 F.2d 897 (1986) (holding that a single copy of graduate thesis on file in one library in Freiburg. Germany invalidated patent claim); Egbert v. Lippmann, 104 U.S. 333 (1881) (holding that a single instance of claimed corset stay, in use in corset of inventor's fiancé, is enough to invalidate patent under public use bar).

32. See, e.g., Buildex, 849 F.2d at 1464 (holding that a firm offer sent to prospective purchaser was an "on sale" event, despite the fact that the offer was marked "confidential"). See generally Pfaff v. Wells Elecs., Inc., 525 U.S. 55 (1998) (discussing the on-sale bar and nowhere mentioning that a sale must be publicly available to trigger it).

33. Merges \& Duffy, supra note 21 , at 473. 
parties. An inventor's own non-informing use is prior art, whereas a third party's is not. ${ }^{34}$

So, an inventor's own non-informing public use qualifies as a "public use" or "on sale" event as those phrases have been interpreted over the years. In terms of the AIA, this means that an inventor's non-informing public use or sale is a "disclosure" under AIA $\int 102(\mathrm{a})$, by virtue of the facts that (1) the phrases "public use" and "on sale" in AIA \$102(a) implicitly incorporate prior case law, including prior cases on an inventor's own noninforming uses; and (2) "disclosure" in AIA $\int 102(\mathrm{~b})$ means "any legitimate prior art reference under AIA \102(a)," which includes "public use" and "on sale" and therefore an inventor's own non-informing public use prior art.

By the same logic, third-party non-informing uses are not "public uses" or "on sale" events under the traditional case law. They therefore do not qualify as prior art references under AIA $\int 102(\mathrm{a})$, and consequently are not "disclosures" under $\ 102(\mathrm{~b})$. To summarize the argument: the words used to define prior art categories in AIA $\int 102(a)$ implicitly incorporate a long history of case law interpreting those words; and the term "disclosure" in AIA $\ 102(\mathrm{~b})$ is meant to be an omnibus word referring to all prior art references (as understood in light of case law) under AIA $\ 102(\mathrm{a})$.

34. Compare Metallizing Eng'g Co. v. Kenyon Bearing \& Auto Parts Co., 153 F.2d 516 (2d Cir. 1946) (Hand, J.) (holding that an inventor's own sales of output from machine is an on sale event barring a patent on the machine), with W.L. Gore \& Assocs., Inc. v. Garlock, Inc., 721 F.2d 1540 (1983) (holding that a third-party sale of tape from tape-making machine did not bar a patent to an inventor who filed more than one-year after that third-party sale). See generally Woodland Trust v. Flowertree Nursery, 148 F.3d 1368, 1370-71 (Fed. Cir. 1998):

Section 102(b), unlike $\int 102(\mathrm{a})$, is primarily concerned with the policy that encourages an inventor to enter the patent system promptly, while recognizing a one-year period of public knowledge or use or commercial exploitation before the patent application must be filed. Thus an inventor's own prior commercial use, albeit kept secret, may constitute a public use or sale under $\int 102(\mathrm{~b})$, barring him from obtaining a patent. See Egbert v. Lippmann, 104 U.S. 333, 336 (1881) (holding that an inventor's unobservable prior use was a public use). So under $\int 102(\mathrm{~b})$, third-party prior use is not a bar when that prior use or knowledge is unavailable to the public. See W.L. Gore \& Assocs., Inc. v. Garlock, Inc., 721 F.2d 1540, 1550 (Fed.Cir. 1983) (holding that a third-party secret commercial activity, more than one year before the patent application of another, is not a $\int 102($ b) bar); of. Baxter Int'l, Inc. v. COBE Labs., Inc., 88 F.3d 1054, 1058-59 (Fed. Cir.1996) (holding that a third-party prior use accessible to the public is a $\$ 102(\mathrm{~b})$ bar). 


\section{Aside: On "Secret Disclosures"}

Even if you are sympathetic to the idea that there is a common law element to many important phrases and terms used in patent law, you might object to the conclusion stated just above. There is an obvious textual problem, it would seem, with an argument that the word "disclosure" is meant to include confidential sales, and the use in public of things that are made by but which in no way reveal the details of the underlying invention. Put simply, these sales and uses are in some sense secret. They are not open, widely discoverable, or easily accessible. So how can they be construed to be part of the general class of "disclosures"? Isn't a disclosure something that is open or widely available?

You might think so, but you would be at least partly mistaken. In the Oxford English Dictionary, one definition of "disclose" is "to unclose, unfold, or unfasten." "35 An older definition is given as "to open up to one's own knowledge, to discover." 36 Examples of "disclosure" in the OED include watching an egg hatch or watching a caterpillar emerge from its cocoon. From these definitions we get a sense of disclosure as the opposite of complete "closedness"-but not necessarily as requiring widespread dissemination, or ubiquitous accessibility. Disclosure can be, in these examples, a fairly quiet and small-scale affair. While one meaning in the OED is, as might be expected, "to make openly known," this is only one meaning. The sense of the other meanings is of something that can be much more limited. And so, following this sense of the word, a confidential sale or non-informing public use can be a "disclosure" in that it represents a move away from complete secrecy, or use only inside a highly protected sphere such as within the strict boundaries of a single company. There is room, in other words, for the idea of a "secret disclosure" - a disclosure that goes beyond absolute nondisclosure but not nearly all the way to wide-open and free dissemination. ${ }^{37}$ And since this interpretation makes so much sense in

35. OXFORD ENGLiSH Dictionary (2d ed. 1989; electronic ed. 2009).

36. Id.

37. It should be noted that in one limited context, the federal False Claims Act (FCA), "public disclosure" has been interpreted to cover quite limited disclosures. See, e.g., United States v. Bank of Farmington, 166 F.3d 853, 860 n.5 (7th Cir. 1999), overruled on other grounds by Glaser v. Wound Care Consultants, Inc., 570 F.3d 907 (7th Cir. 2009) ("DD]isclosure to a public official with direct responsibility for the claim in question of allegations or transactions upon which a qui tam claim is based constitutes public disclosure within the meaning of [the FCA]"). However, there are three distinct aspects of FCA cases that bear mentioning, and that strongly suggest that this interpretation is specific only to this statute. First, the limited disclosures here are those made by public officials in their official capacities, which suggests that despite how limited they are in practice they are technically 
light of the history of the words used to define prior art, and the structure of the AIA and prior patent Acts, it appears to be the correct one in this case. ${ }^{38}$

a) Prior-Filed Patent Applications as Secret Disclosures

Another distinctive feature of the AIA is the way the new act handles information contained in the specification of a prior-filed patent or application. Note at the outset that $\int 102(b)(2)$ refers to information in earlier-filed application as "disclosures"-further indication that non-public events qualify as disclosures under the AIA.

In this respect, the AIA carries forward the rule from $\ 102(\mathrm{e})$ of the 1952 Act that information contained in the specification of a prior-filed application or patent is prior art to a later-filed application that claims the same information. This rule derives originally from Justice Oliver Wendell Holmes' opinion in Alexander Milburn v. Davis-Bournonville Co., ${ }^{39}$ and so represents another instance in which common law rulings in patent law are perpetuated in a new generation of statutory enactments. AIA $\int 102(\mathrm{a})(2)$ has

open for general public discovery. Second, the effect of this interpretation is to restrict the filing of dubious claims; once a piece of information is disclosed by a public official it is wasteful to provide incentives under the FCA for private individuals to advance the same information - the purpose of the FCA is already being served by the public action. Third, the phrase "publicly disclosed" interacts closely with the FCA's rule eliminating FCA cases where a private party's notice regarding governmental agency wrongdoing is "based upon" the publicly disclosed information. It is difficult to understand the meaning of public disclosure in this context without understanding what "based upon" means. See, e.g., Glaser v. Wound Care Consultants, Inc., 570 F.3d 907 (7th Cir. 2009) (construing both phrases together). On the overall purpose of the FCA, see Graham County Soil \& Water Conservation Dist. v. United States, 130 S. Ct. 1396 (2010) (construing a provision defining administrative public disclosures as applying to state administrative reports as well as federal ones).

38. This understanding of disclosure is consistent with usage in the trade secret field, and in many other areas of law. See, e.g., Metallurgical Indus., Inc. v. Fourtek, Inc., 790 F.2d 1195 (7th Cir. 1986) ("We conclude that a holder may divulge his information to a limited extent without destroying its status as a trade secret. ... If disclosure to others is made to further the holder's economic interests, it should, in appropriate circumstances, be considered a limited disclosure that does not destroy the requisite secrecy."); see also Henry W. (Hank) Jones III, Licensing in Cyberspace, Understanding the Intellectual Property License (1998), Practising Law Institute, Patents, Copyrights, Trademarks, and Literary Property Course Handbook Series, PLI Order No. G0-002E, 534 PLI/Pat 237, at 247 (reprinting a "Confidential Disclosure" agreement as an exemplar). This is in fact an old meaning of "disclose" in legal circles. See, e.g., Livingston \& Gilchrist v. Maryland. Ins. Co., 11 U.S. 506, 537 (1813) (Story, J.) (discussing the relevance of an insured party's "disclosure" and "nondisclosure" to an insurance firm of details regarding the interest of a Spanish national in a seagoing cargo that was seized by British privateers, giving rise to an insurance claim against the insurance firm; no sense of "disclosure" requiring any publicness, only a communication-presumably in confidence-to the insurance company).

39. 270 U.S. 390 (1926). 
the same basic structure as $\int 102(\mathrm{e})$ of the 1952 Act: it applies whether the prior-filed application has issued as a patent or merely been published; and it creates the same "nunc pro tunc" rule, in that when a prior-filed application is published or issues as a patent, the information within it becomes prior art as of the date of filing. ${ }^{40}$ The major difference is that, unlike under the 1952 Act, the prior-filed patent rule under the AIA applies whether the prior-filed application merely describes the later-filed invention, or also describes and claims that invention. (Recall that overlapping claims were handled under the 1952 Act under $\int 102(\mathrm{~g})$.) The critical date, in other words, is the filing date of the first-filed patent or application. The invention date of the second filer does not matter; there is no "swearing behind" AIA \ 102(a)(2) prior art, as there is for $\int 102(\mathrm{e})$ of the 1952 Act. $^{41}$

\section{3. "Public Disclosure": Meaning and Rationale}

It is abundantly clear by now, I hope, that the AIA uses the word "disclosure" as a term of art whose meaning is drawn from the structure of the Act and the case law that informs the various categories of prior art. This is important to keep in mind as we turn to the next critical aspect of the AIA: the closely related meaning of the term "public disclosure" in AIA $\int 102(\mathrm{~b})$.

The simple and obvious point to be made at the outset is that a public disclosure under AIA $\ 102(\mathrm{~b})$ must necessarily be one that is more widely available, more publicly accessible, than a mere disclosure. "Disclosure" is something that is beyond-though not necessarily far beyond-complete and utter secrecy. So "public disclosure" must be something well beyond limited disclosure. It must mean accessible, at least in theory, to the general public.

This seems clear from the wording of the statute. The contrast between "disclosure" and "public disclosure" in the AIA is too obvious to ignore. But what purpose does it serve? Why did Congress choose to make this distinction? For an answer to that we have to turn back to the statute itself, specifically the grace period provision of AIA \102(b)(1)(B), which eliminates from the prior art disclosures made one year or less before the filing date if:

40. This follows from the language of the statutes. Section 102(e) of the 1952 Act says " No patent if invention described in] a patent granted on an application for patent by another ... ," while AIA $\int 102(\mathrm{a})(2)$ states "[No patent if] the claimed invention was described in a patent issued [to another] . . .."

41. 37 C.F.R. \1.131 (2011) (An "inventor may submit an appropriate oath or declaration to establish invention of the subject matter prior to the effective date of the reference .... The effective date of a U.S. patent [or] U.S. patent application . . is the earlier of its publication date or date that it is effective as a reference under 35 U.S.C. 102(e).'). 
the subject matter disclosed had, before such disclosure, been publicly disclosed by the inventor or a joint inventor or another who obtained the subject matter disclosed directly or indirectly from the inventor or a joint inventor.

The basic idea is this: an inventor earns a grace period when he or she "publicly discloses" before a reference appears in the prior art. This must be read together with the grace period under AIA \$102(b)(1)(A). Taken together, the grace period provision says: A disclosure made one year or less before the effective filing date of a claimed invention shall not be prior art to the claimed invention if: (A) the disclosure was made by the inventor; or (B) the subject matter disclosed had, before such disclosure, been publicly disclosed by the inventor.

Section 102(b)(1)(B), it seems, should be read this way. The relevant "disclosure" in $\int 102(\mathrm{~b})(1)(\mathrm{B})$ is the third-party disclosure. This disclosure will be removed from the prior art only if the inventor has made a prior public disclosure of the same subject matter. When the inventor has done this, the third-party disclosure is removed from the prior art under the subsection.

Yet under these circumstances, the inventor's public disclosure must be analyzed separately under $\int 102(\mathrm{~b})(1)(\mathrm{A})$. That is, the inventor's public disclosure under $\$ 102(\mathrm{~b})(1)(\mathrm{B})$ is also a disclosure "made by the inventor" under $\int 102(\mathrm{~b})(1)(\mathrm{A})$. And under $\ 102(\mathrm{~b})(1)(\mathrm{A})$, this disclosure is removed from the prior art so long as it is within one year of the inventor's filing date.

There are two reasons to read the statute this way. First, the text supports this view. Recall that AIA $\ 102(\mathrm{~b})(1)$ says that a disclosure is removed from the prior art only if that disclosure is made one year or less before the applicant's filing date, and one of two other requirements are met. The oneyear time period applies to the entire subsection, both $\ 102(\mathrm{~b})(1)(\mathrm{A})$ and $(\mathrm{B})$. Then $\ 102(\mathrm{~b})(1)(\mathrm{A})$ and $(\mathrm{B})$ state the alternative additional requirement - the additional condition that must be met, along with the one-year requirement. These alternative requirements, one of which must be satisfied along with the one-year time period, are these: the disclosure has to be either (A) made by the inventor; or (B) made by a third party and preceded by a public disclosure on the part of the inventor. The exception in $\int 102(\mathrm{~b})(1)(\mathrm{B})$, in other words, deals with third-party disclosures. These are the prior art events that, without \$102(b)(1)(B), would bar the novelty of an inventor's application. The situation dealt with in $\int 102(b)(1)(B)$ is a distinct case from $\int 102(b)(1)(A)$. What makes it distinct is that it involves third-party disclosures within a year of an applicant's filing date. The signal that the two situations are distinct is the use of the word "or" between parts $\ 102(\mathrm{~b})(1)(\mathrm{A})$ and $(\mathrm{B})$. 
The second reason to read AIA $\ 102(\mathrm{~b})(1)$ this way is that, otherwise, \$102(b)(1)(B) might seem to create a "super grace period" in cases where a later applicant has made an earlier public disclosure. How could this be? The argument could be made that the one-year time period stated in the introductory phrase of $\int 102(\mathrm{~b})(1)$ applies only to the third-party disclosure and not to the inventor's public disclosure under $\$ 102(\mathrm{~b})(1)(\mathrm{B})$. The language of $\int 102(b)(1)$, remember, is this: "A disclosure made [one] year or less before the effective filing date of a claimed invention shall not be prior art if" (A) happens or (B) happens. Section 102(b)(1)(B) specifically refers to a "disclosure" made by third parties. It covers the case where "before ... disclosure" the inventor has publicly disclosed the same subject matter. The disclosure that is, grammatically speaking, the subject of $\int 102(\mathrm{~b})(1)(\mathrm{B})$ is the third-party disclosure. Collapsing the introductory phrase and paraphrasing, the language states: A disclosure made one year or less before the filing date is not prior art if it is a third-party disclosure and is preceded by an inventor's public disclosure. It is the third-party disclosure that must be preceded by the inventor's public disclosure, if the inventor is to preserve a grace period. So-here is the real point-arguably it is only the third-party disclosure that must be one year or less before filing. Arguably, the one-year time period does not apply to the "public disclosure" in $\int 102(\mathrm{~b})(1)(\mathrm{B})$, because this is, in the terms of the statute, not the subject of $\$ 102(\mathrm{~b})(1)(\mathrm{B})$, not the "disclosure" that is removed from the prior art in $\$ 102(\mathrm{~b})(1)(\mathrm{B})$. Put simply, the "disclosure" of $\int 102(\mathrm{~b})(1)(B)$ is the third-party disclosure, and the oneyear time limit applies only to this disclosure and not the act of an inventor who is seeking to avoid the prior art effect of this disclosure.

If the statute were read this way, then an inventor who publicly discloses on January 1 of Year 1 would not set a one-year clock running by virtue of that public disclosure in the event that a third party later made a disclosure, say on June 1 of Year 3. Under these facts only on June 1 of Year 3 would the one-year period begin to run. That is so because only a third-party disclosure made one year or less before the applicant's filing can be removed from the prior art under AIA $\ 102(\mathrm{~b})(1)(\mathrm{B})$. A third-party disclosure made more than a year before the applicant's filing date cannot be removed. So, in that case, the inventor's earlier public disclosure cannot save him or her. But the fact remains that unless the inventor's public disclosure is analyzed separately it does not seem to be subject to the one-year limiting grace period under $\int 102(\mathrm{~b})(1)(\mathrm{B})$. The inventor's public disclosure under $\int 102(\mathrm{~b})(1)(\mathrm{B})$ is not the disclosure, made a year or less before filing, whose prior art status is affected by $\int 102(\mathrm{~b})(1)(\mathrm{B})$; it is the third party's disclosure that shall not be prior art under $\$ 102(\mathrm{~b})(1)(\mathrm{B})$ if the conditions of $\$ 102(\mathrm{~b})(1)(\mathrm{B})$ are met. Put differently, the effect of $\int 102(b)(1)(B)$ is to remove a third-party disclosure 
from the prior art; so this is the disclosure, made a year or less before the inventor's filing, which is the focus of $\int 102(\mathrm{~b})(1)(\mathrm{B})$. The introductory phrase uses the same term as is used to refer to the third-party disclosure in $\int 102(\mathrm{~b})(1)(\mathrm{B})$, so it is this third-party disclosure that is subject to the oneyear limitation described in the introductory phrase.

The solution, as argued earlier, is to view a "public disclosure" as in essence two separate events. It is first a "disclosure by the inventor" under AIA $\int 102(B)(1)(A)$. But it is also one component of a third-party disclosure situation under $\int 102(\mathrm{~b})(1)(\mathrm{B})$; to be precise, it is the one act on the part of the inventor that can remove third-party disclosures from the prior art, so long as both those third-party disclosures and the inventor's public disclosure are one year or less from the inventor's filing date. The crucial advantage to reading the statute this way is that the applicant must still file within one year of his or her own public disclosure in order to preserve patentability. The rationale, again, is that although an inventor's public disclosure removes a third-party reference under $\int 102(\mathrm{~b})(1)(\mathrm{B})$, it is also a regular inventor's-own disclosure under $\int 102(\mathrm{~b})(1)(\mathrm{A})$. And therefore it is subject to the one-year time limit stated in the introductory language in $\$ 102(\mathrm{~b})(1)$, by virtue of the fact that it is covered under $\int 102(\mathrm{~b})(1)(\mathrm{A}){ }^{42}$

For this argument to win out, it is apparent that a "public disclosure" under AIA $\int 102(\mathrm{~b})(1)(\mathrm{B})$ must also qualify as a "disclosure that was made by the inventor" under $\int 102(\mathrm{~b})(1)(\mathrm{A})$. But this seems quite logical. A public disclosure is, after all, a special type of disclosure. The smaller class-public disclosures - is included in the larger class, disclosures. It is a subset of the larger class. To put it in patent terms, "public disclosures" reads like a dependent claim, and anything that infringes a dependent claim must also of course infringe the independent claim on which (or from which) the dependent claim depends. ${ }^{43}$ Put simply, a public disclosure capable of removing a third-party reference under AIA $\int 102(\mathrm{~b})(1)(\mathrm{B})$ is a species of the larger genus of “inventor's disclosure" under $\$ 102(\mathrm{~b})(1)(\mathrm{A})$. This particular species plays two roles: it is a normal inventor's-own disclosure, and it is also an event that removes third-party disclosures from the prior art. As a normal inventor's-own disclosure, it is subject to the one-year limitation of

42. Collapsing and paraphrasing the language of AIA $\int 102(b)(1)$ helps to show what I mean: "A disclosure made one year or less before the effective filing date of a claimed invention shall not be prior art to the claimed invention if (A) the disclosure was made by the inventor ... or (B) [the disclosure was by a third party and was preceded by a public disclosure on the part of the inventor] ...." AIA $\int 102(\mathrm{~b})(1)$.

43. On dependent claims see Merges \& Duffy, supra note 21, at 30-31. 
\ 102(b)(1)(A). As a public disclosure, it removes third-party disclosures from the prior art under $\int 102(\mathrm{~b})(1)(\mathrm{B})$.

a) Explaining "Public Disclosure" and the Grace Period: Policy Rationale

The animating idea behind the new grace period seems to be this: to earn a grace period as against a third party who has begun to bring an invention to the attention of the public, an inventor must confer some benefit on the public. The price of the grace period when a third party is willing to disclose, in other words, is something beyond a technical or limited disclosure. What is required is a full-on public disclosure. That is the essence of the new thirdparty grace period under AIA $\ 102(\mathrm{~b})(1)(\mathrm{B})$.

Why might this make sense? Consider the difference between a secret or highly limited disclosure_-say, for example, a confidential sale_-and a widely accessible public disclosure. This explanation depends on accepting a lack of symmetry in the AIA's treatment of disclosures. A secret disclosure made by the inventor him- or herself begins the one-year grace period. But a secret disclosure on the part of a third party does not. The explanation lies in one of the traditional justifications for the statutory bars under the 1952 Act. From the earliest cases in this area, most notably Pennock v. Dialogue, ${ }^{44}$ the courts expressed concern that an inventor who commercializes an invention prior to filing a patent application could thereby extend the monopoly period or term of protection set by the Patent Act. A long period of commercialization, when tacked onto the normal patent term, might create in effect a "super patent." 45 Ten years of pre-filing commercialization, for example, when joined to an average patent term of seventeen years, would amount to an effective period of exclusivity totaling twenty-seven years. To prevent this, the statutory bars were interpreted strictly: any commercialization activity more than a year before filing was thought to run afoul of this "no extension of monopoly" policy. ${ }^{46}$ And so was born the notion that even secret sales or non-informing public uses more than a year before filing were enough to invalidate a patent. The way to prevent monopoly extensions, in other words, was to force inventors to "hurry up and file."

44. 27 U.S. 1 (1829) (Story, J.). See generally Merges \& Duffy, supra note 21, at 525-26 (discussing Pennock and its implications).

45. See id. at 591 (discussing cases raising "monopoly-extension policy" problem).

46. See, e.g., Pfaff v. Wells Elec., Inc., 525 U.S. 55 (1998) (holding that sales confirmation that came eleven days before critical date barred patent; effective extension of one year plus eleven days, in other words, deemed to violate statutory policy). 
The statutory bars under $\$ 102(\mathrm{~b})$ of the 1952 Act applied to all parties, inventors and third parties alike. But the "hurry up and file" policy was always an awkward fit where third-party statutory bar activities were concerned. Why should an inventor, who is very likely not even aware of an obscure third-party prior art event, be subject to the running of a one-year clock when that inventor never knew the clock had even started to tick? One answer might be that the strict application of the one-year time bar might have the general effect of encouraging an inventor to file. One can never be sure if a clock was set running earlier by a third party, so the best practice might be to file as soon after inventing something as possible. But of course this rationale completely undercuts the notion of a grace period-a safe period of time after a prior art event during which an inventor can still preserve his or her patent rights. Under the right facts, where a third party creates a valid prior art reference close to a year prior to an inventor's invention date, the effective grace period might be vanishingly short. And in addition, if the "hurry up and file" policy is to be paramount, there are better ways of achieving it than tying patent validity to third-party events more than a year before filing. The easiest way is to adopt an "absolute novelty" standard such as that in effect in the European Patent Office: any prior art reference with an effective date prior to the applicant's filing date bars patentability, period. The truth is that the Patent Act has always sought to balance "hurry up and file" with a true break for inventors, in the form of a grace period. ${ }^{47}$

By design, or perhaps by happenstance, the AIA seems to have done a reasonably good job of balancing these policies. I say this for two reasons. First, the AIA carries forward the distinction between inventor's-own secret disclosures and third-party secret disclosures. As with preexisting case law, the AIA says that the former are prior art events, while the latter are not. This has the effect of discouraging an inventor's early commercialization, and thus furthering the "no extension of monopoly" policy, while not punishing an inventor for ultra-obscure, secret third-party activities that would otherwise shorten the effective grace period.

Second, the AIA permits an inventor to safeguard against the effects of third-party prior art by publicly disclosing his or her invention. Public disclosure immunizes the inventor against the prior art effect of third-party disclosures. By publicly disclosing, the inventor removes any third-party prior references that come after public disclosure. One interesting result of this

47. Merges \& Duffy, supra note 21, at 528 (discussing the U.S. grace period throughout history). 
new rule is that the inventor can seize control over the one-year clock that applies to his or her invention. The inventor who decides to publicly disclose an invention has in effect chosen the date on which the one-year clock begins to run. A third party that makes a subsequent disclosure cannot alter this. The inventor, having set the clock running, no longer has to worry about clock-related effects of third party activities. The choice to publicly disclose takes away the power of third parties to undermine the inventor's grace period.

Even so, two practical points must be emphasized. First, under AIA $\int 102(\mathrm{~b})(1)(\mathrm{B})$, the disclosure strategy described above only works if the inventor's public disclosure precedes any and all third-party disclosures. If a third party manages to slip a valid disclosure into the prior art before the inventor publicly discloses, all bets are off. The undetected clock issue appears again and the inventor is out of luck, or at any rate subject to a oneyear period that begins before he or she is aware of it. Second, public disclosure may be the answer to lots of third-party prior art problems, but it may come with some downside risks. The pressure toward early public disclosure forces an inventor to preserve patent rights at the cost of destroying trade secret status for an invention. The choice of whether to rely on patenting or trade secrecy may be difficult, especially in the period just after an invention is made. Product possibilities, market conditions, funding sources-all may be uncertain when a raw technology has just been developed. Public disclosure undoubtedly gives the inventor a strong leg up in the patent game-but it may turn out that this is not the right game to play with a given invention.

That said, there are two mitigating tactics available to soften the impact of this tough choice. First, an inventor can file a provisional patent application, which buys time in the same way as a public disclosure (more if a normal application is filed only at the very end of the one-year provisional period-with the eighteen-month publication window measured from the filing date of the normal or standard application, this preserves trade secrecy for up to two and a half years after the provisional is filed); and second, the AIA's prior user right arguably gives a boost for those who choose the path of trade secret protection. Even so, the need to decide early whether to earn a reliable one-year grace period via public disclosure, or rely on trade secrecy, may put many an inventor to a very difficult decision before a great deal of information is available.

b) Prior-filed Applications and Public Disclosures

Information disclosed in a prior-filed patent application or patent is part of the prior art under AIA $\int 102(\mathrm{a})(2)$, just as it is under $\ 102(\mathrm{e})$ of the 1952 
Act. However, as with other prior art under AIA \101(a)(1), there is a special exception, found in AIA $\int 102(\mathrm{~b})(2)$, to the prior art rule of AIA $\int 102(a)(2)$. The exception provides that a later-filing inventor who claims what an earlier-filer discloses in a patent or application can remove that earlier-filed disclosure from the prior art. The way to remove it is to publicly disclose it first. If the subject matter is publicly disclosed before the earlier-filer files an application containing it, the subject matter is removed from the prior art.

Generally, to beat out another person who claims the same subject matter, an inventor must either (1) file first, or (2) fall under the grace period mentioned earlier-by (a) publicly disclosing before the other person's application, and (b) filing within one year of that public disclosure.

It is worth noting that the AIA refers to the information in the prior-filed application as a "disclosure." This is significant for two reasons. First, it lends credence to the argument I made earlier that "disclosure" under the AIA refers to any prior art event defined under the new act. Second, it shows once again that the AIA, by its terms, draws a sharp distinction between a disclosure and a public disclosure. A patent application is confidential until it is published, or until it issues as a patent; it is known only to the Patent and Trademark Office ("PTO") and the applicant. Yet the information in such an application counts as a "disclosure" under the AIA, and thus forms part of the prior art-just as it did under $\int 102(\mathrm{e})$ of the 1952 Act. Once again we see that "disclosure" is best read as "prior art reference," and is to be seen in stark contrast to a "public disclosure," which requires general public accessibility.

The grace period under the AIA is ultimately what justifies the label "first-inventor-to-file." An inventor's public disclosure signals the fact of invention. As long as that inventor files within a year, another inventor who happens to file first is out of luck. The first-discloser/second-filer is truly an inventor, by virtue of his or her earlier disclosure. And so the fact that this inventor did not actually file first is not important. But notice that the proof required to beat out an actual first-filer is substantial. The AIA requires proof of public disclosure, not just any type of prior art disclosure. Because public disclosure requires that prior art be made widely or generally accessible, this excludes obscure types of prior art. It follows that an inventor who can establish prior public disclosure will have convincing proof that he or she had possession and knowledge of the invention on a date prior to another person's filing of a patent application. Hence the label "first-proveninventor-to-file." It takes solid proof to earn the grace period; and this means that actual first-filers will be beat out only by inventors who have a solid claim to the status of earlier inventor. 


\section{CONCLUSION: CONTINUITY AND CHANGE IN THE PATENT SYSTEM}

The AIA undoubtedly represents a sea change in the structure of the U.S. patent system. It replaces the venerable first-to-invent priority rule with firstinventor-to-file. And, in the process, it consolidates and modifies the foundational rules pertaining to patentable novelty. This is a big deal, by any measure.

And yet, terminology employed in describing novelty in the U.S. patent system is so deeply rooted historically that there is much more continuity built into the AIA than appears at first. So under the AIA the date when a reference becomes prior art has now changed in many cases, but the definitions of which events constitute prior art have for the most part not changed. The temporal element is new, but the AIA preserves an important part of the basic fabric of the prior art, in the form of the precise definitions of which events and what types of information will be said to count against the novelty of a patent application.

In addition, the AIA preserves and perpetuates the U.S. patent system's commitment to a grace period. While the AIA moves the United States to a first-inventor-to-file system, it does not go all the way to complete international harmonization. In particular, the AIA diverges from the international norm which approximates an "absolute novelty" standard. So even beyond the level of terminology, there is much in the AIA that shows a deep connection to the long history of U.S. patent law. When AIA cases finally reach the PTO and the courts, it would be wise for all involved to keep this point in mind. There is much that is new, and certainly much that is complex. But there is much also that ties the new AIA regime to the broad and deep history of patent protection in the United States. 